OPEN ACCESS

Edited by:

Maria João Fraqueza,

Universidade de Lisboa, Portugal

Reviewed by:

Giulia Tabanelli,

Università degli Studi di Bologna, Italy

Alexandra Lianou,

Agricultural University of Athens,

Greece

${ }^{*}$ Correspondence:

Frédéric Leroy

frederic.leroy@vub.be

Specialty section:

This article was submitted to

Food Microbiology,

a section of the journal

Frontiers in Microbiology

Received: 18 June 2018

Accepted: 31 August 2018 Published: 19 September 2018

Citation:

Stavropoulou DA, De Maere $H$ Berardo A, Janssens B, Filippou P, De Vuyst L, De Smet $S$ and Leroy $F$ (2018) Species Pervasiveness Within the Group of Coagulase-Negative Staphylococci Associated With Meat Fermentation Is Modulated by $\mathrm{pH}$. Front. Microbiol. 9:2232. doi: 10.3389/fmicb.2018.02232

\section{Species Pervasiveness Within the Group of Coagulase-Negative Staphylococci Associated With Meat Fermentation Is Modulated by $\mathrm{pH}$}

\author{
Despoina Angeliki Stavropoulou', Hannelore De Maere ${ }^{2}$, Alberto Berardo $^{3}$, \\ Bente Janssens ${ }^{1}$, Panagiota Filippou ${ }^{1}$, Luc De Vuyst ${ }^{1}$, Stefaan De Smet ${ }^{3}$ and \\ Frédéric Leroy ${ }^{1 *}$
}

${ }^{1}$ Research Group of Industrial Microbiology and Food Biotechnology, Faculty of Sciences and Bioengineering Sciences, Vrije Universiteit Brussel, Brussels, Belgium, ${ }^{2}$ Research Group for Technology and Quality of Animal Products, KU Leuven, Technology Campus Ghent, Ghent, Belgium, ${ }^{3}$ Laboratory for Animal Nutrition and Animal Product Quality, Department of Animal Production, Ghent University, Ghent, Belgium

During spontaneous meat fermentations, Staphylococcus equorum, Staphylococcus saprophyticus, and Staphylococcus xylosus are generally the most prevailing species within the communities of coagulase-negative staphylococci (CNS). There is an interest to introduce CNS isolates from artisan-style spontaneous meat fermentations as starter cultures in more industrialized processes, as to confer additional quality benefits. However, staphylococcal competitiveness within the meat matrix is affected by the processing conditions, which vary considerably among product types. A major factor of variability relates to the intensity of acidification, driven by the concentration of added carbohydrates. The effect of $\mathrm{pH}$ on CNS prevalence was studied in both a mince-based meat fermentation model and in fermented sausages produced on pilot scale. Roughly, from all experiments combined, it appeared that a $\mathrm{pH}$ of 5.3 corresponded with a breakpoint for CNS selection. Above this value, a general prevalence by $S$. xylosus was found, even overruling the addition of starter cultures consisting of $S$. equorum and S. saprophyticus strains. At pH values below 5.3, S. xylosus was also accompanied by $S$. equorum (following a mild $\mathrm{pH}$ drop) and $S$. saprophyticus (following a stronger $\mathrm{pH}$ drop). Still, addition of starter cultures affected the volatile profile compared to the control batch, even if those starter cultures were not able to dominate during the ripening process. This study nonetheless provides a warning for an overly confident use of specific CNS species as starter cultures, especially when in a given processing context the prevailing conditions do not allow superior growth compared to the CNS from the background microbiota.

\footnotetext{
Keywords: Staphylococcus xylosus, Staphylococcus equorum, Staphylococcus saprophyticus, starter cultures, dry fermented sausages, $\mathrm{pH}$
}

\section{INTRODUCTION}

Coagulase-negative staphylococci (CNS) are fundamental to the process of meat fermentation, whereby their metabolic activities contribute to the development of qualitative end-products (Sánchez Mainar et al., 2017). In contemporary meat processing plants, the production of fermented meats is now habitually performed by addition of a starter culture based on a mixture 
of selected lactic acid bacteria (LAB) and CNS strains to allow more control over the process (Leroy et al., 2006). For some products, the artisan-type technique of spontaneous fermentation is still in use, albeit rarely on an industrial scale (Talon et al., 2007; Coton et al., 2010; Janssens et al., 2013; Leroy et al., 2015). In spontaneously fermented variants, Staphylococcus equorum, Staphylococcus saprophyticus, and/or Staphylococcus xylosus are usually the (co)dominant CNS species, besides a wide diversity of other minor species (Mauriello et al., 2004; Corbière Morot-Bizot et al., 2006; Iacumin et al., 2006, 2012; Drosinos et al., 2007; Marty et al., 2012; Greppi et al., 2015; Pisacane et al., 2015; Ratsimba et al., 2017). The species composition of staphylococcal consortia in fermented meats is nevertheless difficult to predict, as this largely depends on the processing parameters applied (Leroy et al., 2014). The acidification level is one of the main factors shaping the CNS microbiota during meat fermentation, whether they are added as starter cultures or not (Stavropoulou et al., 2018a,b). For instance, S. xylosus often dominates in Southern-European type of fermented sausages that are characterized by mild pH values (Cocolin et al., 2001a; Rossi et al., 2001; Iacumin et al., 2006; Di Cagno et al., 2008; Greppi et al., 2015), whereas Staphylococcus carnosus is uncommon in spontaneous fermentations and seems to be more adapted to highly acidified sausages (Stahnke et al., 2002; Stavropoulou et al., 2018a). The speed and extent of acidification are set by the degree of carbohydrates available, the fermentation temperature, and the use of acidifying LAB strains. Surface molding, common in many types of fermented sausages, also affects the $\mathrm{pH}$ through the consumption of lactic acid and, thus, modulates staphylococcal composition as well (Janssens et al., 2013).

With respect to starter culture formulation, S. carnosus and/or S. xylosus are the two CNS species that are widely used by the meat fermentation industry and which have been studied thoroughly with respect to their technological properties (Beck et al., 2002, 2004; Olesen et al., 2004; Tjener et al., 2004; Casaburi et al., 2005; Leroy et al., 2006, 2017; Rosenstein et al., 2009) and their evolution during meat fermentation (Di Maria et al., 2002; Corbière Morot-Bizot et al., 2007; Stavropoulou et al., 2018a). Although other CNS species than the latter two have been studied for their technologically relevant features (Villani et al., 2007; Talon et al., 2008; Bonomo et al., 2011; Casquete et al., 2011; Fonseca et al., 2013a,c; Prpich et al., 2016), usually only a few studies monitor their prevalence after inoculation as novel starter culture candidates (Corbière Morot-Bizot et al., 2007; Talon et al., 2008; Fonseca et al., 2013c; Sánchez Mainar and Leroy, 2015). The ability of starter cultures to persist during meat fermentation with respect to the background microbiota depends on the processing parameters and this is not always guaranteed, for instance because of the different degrees of acidification driven by the carbohydrate concentrations added (Villani et al., 2007; Sánchez Mainar and Leroy, 2015; Stavropoulou et al., 2018a).

In the current study, the effect of the acidification level on CNS communities during meat fermentation was investigated in a mince-based meat model system as well as during actual dry fermented sausage production on pilot scale. Focus was placed on the relative pervasiveness of $S$. equorum, S. saprophyticus, and
S. xylosus, both with respect to their spontaneous outgrowth and when added as starter cultures.

\section{MATERIALS AND METHODS}

\section{Bacterial Strains, Media, and Inoculum Build-Up}

The three CNS strains, namely $S$. equorum DFL-S19, S. saprophyticus FPS1, and $S$. xylosus 2S7-2, and the LAB strain (Lactobacillus sakei CTC 494) were used in this study, originating from the culture collection of the research group of Industrial Microbiology and Food Biotechnology (Vrije Universiteit Brussel, Brussels, Belgium). The CNS strains were selected based on their ability to produce volatile compounds during an in vitro assay (Stavropoulou et al., 2015). They were stored at $-80^{\circ} \mathrm{C}$ in glycerol-containing $(25 \%, v / v)$ brain heart infusion (BHI) medium (Oxoid, Basingstoke, Hampshire, United Kingdom) for the CNS or de Man-Rogosa-Sharpe (MRS) medium (Oxoid) for the LAB. For the inoculum build-up, all strains were propagated twice in the appropriate media and incubated at $30^{\circ} \mathrm{C}$ for $12 \mathrm{~h}$. The precultures were then inoculated $(1 \%, \mathrm{v} / \mathrm{v})$ into BHI or MRS medium for the final inoculum at $30^{\circ} \mathrm{C}$ for $12 \mathrm{~h}$. Cell pellets were collected by centrifugation $\left(8041 \times g\right.$ at $4^{\circ} \mathrm{C}$ for $\left.20 \mathrm{~min}\right)$ and used as inoculum for the sausage preparation after re-suspension in saline solution (0.85\%, m/v, NaCl; VWR International, Darmstadt, Germany).

\section{Meat Fermentations by Means of a Mince-Based Meat Model}

The effect of the acidification level on the CNS community dynamics was studied in a mince-based meat model system that was used to carry out the meat fermentations. The total prepared meat batter consisted of fresh pork mince $(3 \mathrm{~kg})$, supplemented with $2.5 \%$ of sodium chloride $(\mathrm{m} / \mathrm{m}$; VWR International), 500 ppm of ascorbic acid (Sigma-Aldrich, Steinheim, Germany), $200 \mathrm{ppm}$ of sodium nitrate (VWR International), and $200 \mathrm{ppm}$ of $\mathrm{MnSO}_{4} \cdot 4 \mathrm{H}_{2} \mathrm{O}$ to stimulate LAB growth (VWR International). The meat batter was inoculated with L. sakei CTC 494 at a level of approximately $6.0 \mathrm{log}$ of colony forming units (cfu) per gram. Two different batches were prepared by adding different glucose (VWR International) concentrations to achieve a strong $(0.7 \%, \mathrm{~m} / \mathrm{m})$ or mild $(0.1 \%, \mathrm{~m} / \mathrm{m}) \mathrm{pH}$ decrease during the fermentation courses. In addition, for each glucose level a different temperature profile was applied to obtain two distinct $\mathrm{pH}$ profiles of strong and mild acidification, corresponding with what is usually applied in North and South Europe, respectively (Table 1). The meat mixture of each batch was stuffed into 60-ml plastic containers (approximately $100 \mathrm{~g}$ per container; VWR International) to enable fermentation in the absence of air. The containers were placed in a water bath coupled to a cryostat (Frigomix 3000T; Sartorius, Goettingen, Germany) and the fermentations were followed for 7 days. Bacterial counts and $\mathrm{pH}$ measurements were performed at days 1, 2, 3, 4, and 7. For each time point, three randomly selected containers were selected for analysis. 
TABLE 1 | Temperature profiles used for the meat fermentation experiments by means of a mince-based meat model.

\begin{tabular}{|c|c|c|}
\hline \multirow[t]{2}{*}{ Profile/Time (days) } & $\begin{array}{c}\text { Strong } \\
\text { acidification } \\
(0.7 \% \text { glucose, } \\
\mathrm{m} / \mathrm{m})\end{array}$ & $\begin{array}{c}\text { Mild acidification } \\
(0.1 \% \text { glucose } \\
\mathrm{m} / \mathrm{m})\end{array}$ \\
\hline & \multicolumn{2}{|c|}{ Temperature $\left({ }^{\circ} \mathrm{C}\right)$} \\
\hline 0 & 25 & 20 \\
\hline 1 & 25 & 20 \\
\hline 2 & 25 & 20 \\
\hline 3 & 20 & 18 \\
\hline 4 & 18 & 16 \\
\hline 5 & 16 & 14 \\
\hline 6 & 14 & 14 \\
\hline 7 & 14 & 14 \\
\hline
\end{tabular}

\section{Pilot-Scale Production of Dry Fermented Sausages}

Fermented sausages were produced in a pilot-scale plant at the Technology Campus Ghent (KU Leuven, Ghent, Belgium). For their preparation, the following basic ingredients were mixed (in $\%, \mathrm{~m} / \mathrm{m}$ ): cutter lean pork (70.5), pork backfat (27.0), sodium chloride (2.5), sodium ascorbate (0.05), and sodium nitrate $(0.015)$. The meat batter was stuffed into collagen casings of $50 \mathrm{~mm}$ diameter (Naturin, Weinheim, Germany), which were dipped in a sorbate solution. The total sausage batter was around $30 \mathrm{~kg}$, whereas the initial mass of each fermented sausage was approximately $200 \mathrm{~g}$. The sausages were ripened in a climate chamber (Kerres Anlagensysteme, Backnang, Germany) for 28 days. The fermentation step lasted 2 or 4 days for the experiments without or with carbohydrates added, respectively (see below), i.e., before the $\mathrm{pH}$ started to level off. The fermentation step was performed at $24^{\circ} \mathrm{C}$ and a relative humidity of $94 \%$. For the ripening process, the temperature was decreased to $12^{\circ} \mathrm{C}$ and the relative humidity was adjusted to $80 \%$ for the last 10 days.

Two different experiments were performed on pilot-scale level. In a first experiment, the aim was to validate the results obtained from the mince-based meat model system in a more realistic set-up. In this case, the meat batter was inoculated with L. sakei CTC 494 solely (6.0 log cfu/g), using two different carbohydrate concentrations added initially $(0.25$ and $0.70 \%$ of glucose, $\mathrm{m} / \mathrm{m}$ ), to be able to test the impact of the acidification level on the dynamics of the autochthonous CNS communities in two batches differing in $\mathrm{pH}$ evolution.

In a second experimental set-up, the fate of the three different CNS strains applied (S. equorum DFL-S19, S. saprophyticus FPS1, and S. xylosus 2S7-2) was investigated during a specific sausage fermentation process characterized by a low acidification degree (i.e., no added carbohydrates), as to meet the conditions under which the corresponding species were expected to be most robust. Four different batches were prepared, of which three were based on the inoculation of one of the three CNS strains under investigation and a fourth one consisted of a control batch without the CNS strains. L. sakei CTC 494 was added to all four batches. All strains were inoculated at a level of approximately 6.0 $\log \mathrm{cfu} / \mathrm{g}$.

Three sausages were analyzed per batch and per time point for each experimental set-up. For the first experiment, each variant was produced three times. Samples were taken for the bacterial enumeration and the $\mathrm{pH}$ measurements after inoculation (day 0 ), at the end of the fermentation step (day 2 or 4 ), and at the end of the ripening stage (28 days). The CNS communities were analyzed at the end of the ripening stage. For the second experiment, additional samples were taken after 1, 7, 14 , and 21 days and survival of the starter culture was followed throughout the production process $(2,14$, and 28 days). The experiment was repeated two times.

\section{pH Measurements}

The $\mathrm{pH}$ of each sample of the mince-based meat model and pilot-scale meat fermentation experiments was measured using a DY-P10 pH meter (Sartorius). Regarding the mince-based meat model fermentation samples, one randomly selected container was used, and triplicate measurements were performed. For the pilot-scale sausage production samples, the $\mathrm{pH}$ measurements were performed for three randomly selected sausages per experimental variant.

\section{Enumeration and Isolation of Microorganisms}

Either $12 \mathrm{~g}$ of the mince-based meat model fermentation samples or $25 \mathrm{~g}$ of the pilot-scale sausage production samples were aseptically transferred into a stomacher bag (Seward, Worthing, West Sussex, United Kingdom) together with 108 or $225 \mathrm{ml}$ of maximum recovery diluents [sterile solution of $0.85 \%(\mathrm{~m} / \mathrm{v}) \mathrm{NaCl}$ (VWR International) and $0.1 \%(\mathrm{~m} / \mathrm{v})$ bacteriological peptone (Oxoid)], respectively. This mixture was homogenized at high speed for $2 \mathrm{~min}$ in a stomacher (Stomacher 400; Seward). Appropriate decimal dilutions in saline were prepared and spread on MRS agar and mannitol salt-phenol-red agar (MSA; VWR International) media. The agar media were incubated at $30^{\circ} \mathrm{C}$ for $48-72 \mathrm{~h}$ and the counts were determined from agar media containing $30-300$ colonies. Next, $10-30 \%$ of the colonies were randomly picked up to analyze the LAB and CNS communities. The MSA- and MRS agar-derived colonies were transferred into BHI and MRS broth media, respectively, and incubated at $30^{\circ} \mathrm{C}$ overnight. The cultures obtained were stored at $-80^{\circ} \mathrm{C}$ in cryovials, containing the appropriate media and $25 \%(\mathrm{v} / \mathrm{v})$ of glycerol, and used for DNA extraction.

\section{Classification and Identification of Bacterial Isolates Through (GTG) 5 -PCR Fingerprinting of Genomic DNA}

Genomic DNA extraction from cell pellets obtained by microcentrifugation at $13,000 \mathrm{rpm}$ of $1.5 \mathrm{ml}$ of an overnight LAB and CNS culture was performed with a Nucleospin 96 tissue kit (Macherey-Nagel, Düren, Germany), according to the manufacturer's instructions. Prior to extraction, the cell pellets 
were washed with Tris-ethylene diaminotetraacetic acid (EDTA)sucrose buffer [TES buffer; $50 \mathrm{mM}$ Tris base (Calbiochem, Darmstadt, Germany), $1 \mathrm{mM}$ EDTA (Sigma-Aldrich), and 6.7\% $(\mathrm{m} / \mathrm{v})$ sucrose (VWR International), $\mathrm{pH}$ 8.0]. Subsequently, (GTG) $)_{5}$-PCR fingerprints of the genomic DNA were obtained, followed by image analysis, as described previously (Braem et al., 2011). Numerical analysis of the fingerprints obtained was performed with BioNumerics 5.1 software (Applied Maths, Sint-Martens-Latem, Belgium). Confirmation of the species identity assigned to each LAB and CNS cluster was done by sequencing of the $16 \mathrm{~S}$ rRNA and $r p o B$ genes of representative isolates, respectively, as described previously (Braem et al., 2011).

\section{Determination of Volatile Compounds}

Volatile compounds produced during the second pilot-scale experiment were measured by solid-phase microextraction (SPME) and gas chromatography coupled to mass spectrometry (GC-MS). Samples were prepared in triplicates in headspace vials containing $5 \mathrm{~g}$ of meat sample and $1 \mathrm{~g}$ of sodium chloride to enhance volatility (Kolb and Ettre, 2006). Analyses were performed with an Agilent 6890 gas chromatograph (Agilent Technologies; Santa Clara, CA, United States), with a MPS2 Gerstel autosampler (Gerstel GmbH \& Co., KG, Mülheim-ander-Ruhr, Germany), and coupled to an Agilent 5973N mass spectrometer (Agilent Technologies). The capillary column used was a J\&W 122-7333 DB-WAXetr $(30 \mathrm{~m} \times 0.25 \mathrm{~mm} \times 0.50 \mu \mathrm{m}$; Agilent Technologies) and the SPME device (Supelco, Bellefonte, PA, United States) was equipped with a $75-\mu \mathrm{m}$ divinylbenzene/carboxen/polydimethylsiloxane (DVS/CAR/ PDMS) fiber. Helium was used as carrier gas with a flow rate of $1.0 \mathrm{ml} / \mathrm{min}$. Samples were equilibrated by agitation at $60^{\circ} \mathrm{C}$ for $40 \mathrm{~min}$ prior to injection. The injection port was set in splitless mode (bake-out of the needle at $260^{\circ} \mathrm{C}$ for $10 \mathrm{~min}$, incubation at $60^{\circ} \mathrm{C}$ for $5 \mathrm{~min}$, and extraction for $30 \mathrm{~min}$ ). The injection volume was set at $1 \mathrm{ml}$, at a rate of $500 \mu \mathrm{l} / \mathrm{s}$. The oven temperature program consisted of an initial step at $28^{\circ} \mathrm{C}$ for $3 \mathrm{~min}$, followed by a linear increase from 28 to $220^{\circ} \mathrm{C}$ at $20^{\circ} \mathrm{C} / \mathrm{min}$. Finally, the temperature remained constant at $220^{\circ} \mathrm{C}$ for $5 \mathrm{~min}$. The temperature of the transfer line was held at $280^{\circ} \mathrm{C}$. Detection was done by an MS detector (ionization energy $70 \mathrm{eV}, 4.1 \mathrm{scans} / \mathrm{s}$, source $230^{\circ} \mathrm{C}$, scan range $29-250 \mathrm{~m} / \mathrm{z}$ ). Identification of the peaks was done by comparison with standard compounds that were injected separately and with library data (NIST $08^{1}$ ). The peak areas of the examined compounds were considered only in case they exceeded three times the baseline signal (Aguinaga et al., 2008). All values were expressed as peak areas.

\section{Statistics}

Using SPSS version 20 (IBM Corporation, Armonk, NY, United States), a Kruskal-Wallis test was used to check for overall significant differences in metabolite production between batches, followed by Mann-Whitney tests as non-parametric two-sample tests for the comparison of values.

\footnotetext{
${ }^{1}$ https://www.nist.gov
}

\section{RESULTS}

\section{Meat Fermentations by Means of a Mince-Based Meat Model}

Due to the two different initial glucose concentrations added in combination with the applied temperature profiles, two different acidification profiles were obtained (Figure 1). For the meat batter with the mild acidification profile, the $\mathrm{pH}$ dropped from 5.8 to around 5.2 after 3 days of fermentation, after which it more or less stabilized (Figure 1A). This evolution paralleled the bacterial counts measured on MRS agar, which increased from 5.73 to $8.71 \mathrm{log} \mathrm{cfu} / \mathrm{g}$ after 3 days of fermentation and then remained stable till the end of the experiment. The MSAderived bacterial counts increased from 3.75 to $5.36 \log \mathrm{cfu} / \mathrm{g}$ after 1 day of fermentation and subsequently fluctuated between the values of 4.87 and $5.51 \mathrm{log} \mathrm{cfu} / \mathrm{g}$. During the fermentation with the strong acidification set-up, the $\mathrm{pH}$ decreased to 4.7 after 4 days of fermentation and remained stable till the end of the experiment (Figure 1C). After fermentation, the LAB population had increased to $9.05 \mathrm{log} \mathrm{cfu} / \mathrm{g}$ and then remained around this value, which was slightly higher than in the mildly acidified variants. The MSA counts slowly increased to their maximum of $4.74 \log \mathrm{cfu} / \mathrm{g}$ after 4 days of fermentation and were estimated at $4.55 \mathrm{log} \mathrm{cfu} / \mathrm{g}$ after 7 days.

The initial CNS population of the meat was composed of S. xylosus (57\% of the isolates; $99 \%$ sequence identity, accession number LN554884.1) and S. saprophyticus (43\% of the isolates; 99\% sequence identity, accession number AP008934.1). In the mildly fermented variants, $S$. xylosus became the most prevalent CNS species during the first 2 days of fermentation, during which S. saprophyticus and S. equorum (98\% sequence identity, accession number LM651926.1) were subdominantly present (Figure 1B). After 3 days of fermentation, however, S. equorum took over and represented $86 \%$ of the CNS community. After 7 days, S. equorum and S. xylosus reached more or less equal representation levels of 44 and 56\%, respectively. In the more acidified variants, S. xylosus and S. saprophyticus were the two major CNS species and $S$. equorum was no longer found (Figure 1D). Instead, S. carnosus (98\% sequence identity, accession number AM295250.1) emerged but was only present in low levels after two (9\%) and 7 days (4\%) of fermentation. Whereas S. xylosus and S. saprophyticus were more or less equally present at the beginning of the fermentation, it was ultimately S. saprophyticus that became the leading species $(67 \%$ of the staphylococcal isolates) after 7 days.

\section{Pilot-Scale Dry Fermented Sausage Production Effect of Acidification Profile}

During the first experimental pilot-scale sausage production setup, two different initial glucose levels were used to achieve two distinct acidification profiles generated by spontaneous fermentation (Table 2). When $0.25 \%(\mathrm{~m} / \mathrm{m})$ of glucose was added, the $\mathrm{pH}$ dropped from 5.69 to 5.23 after 4 days of fermentation and then increased at the end of ripening to 5.92 . For the meat batters with $0.70 \%(\mathrm{~m} / \mathrm{m})$ of added glucose, the 


\section{Bacterial counts (log cfu/g)}

A

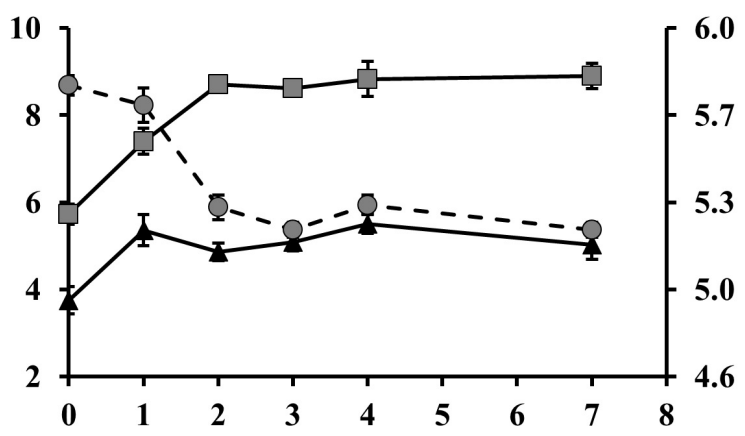

C

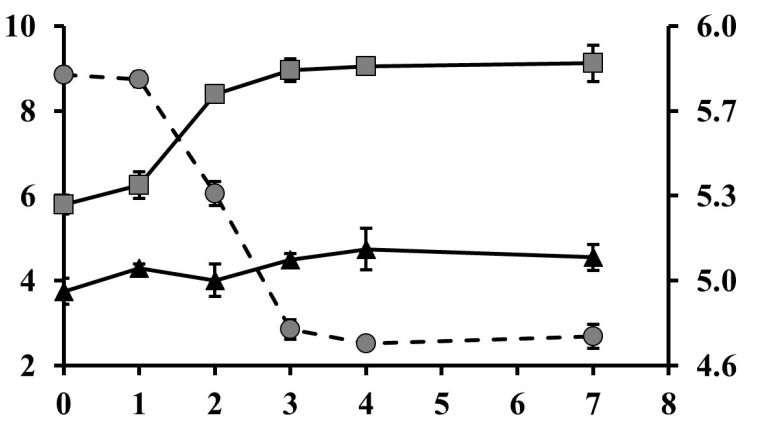

\section{Presence of CNS} isolates (\%)

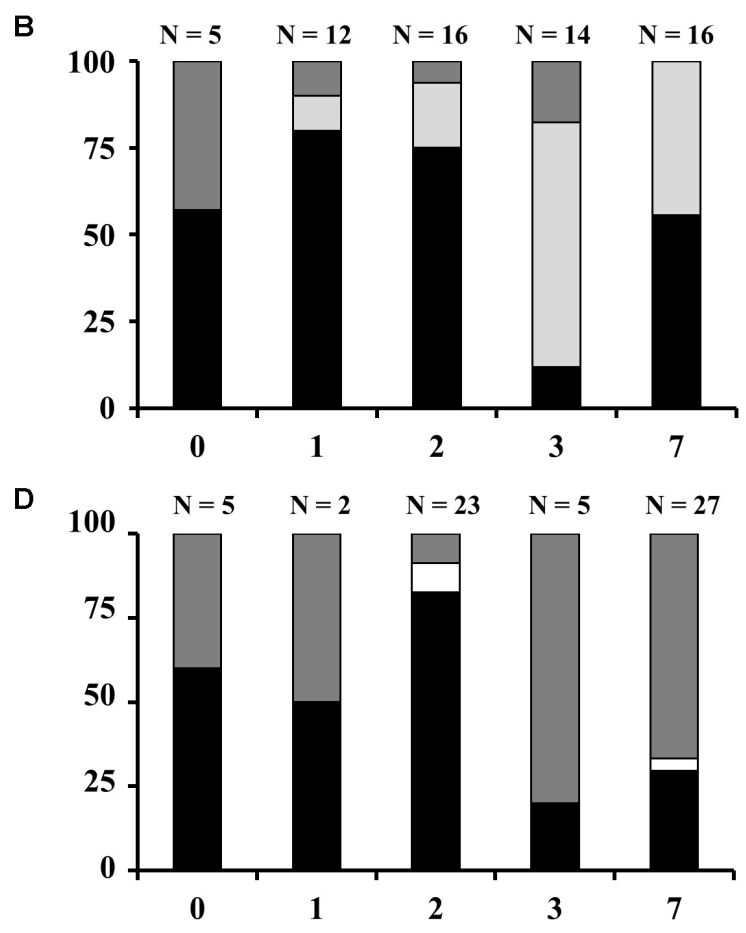

\section{Time (days)}

FIGURE 1 | Counts of lactic acid bacteria (gray squares) and coagulase-negative staphylococci (CNS; black triangles), as well as the pH profiles (gray circles) and the species diversity of the staphylococcal communities of meat fermentations by means of mince-based meat models, inoculated with Lactobacillus sakei CTC 494, and with mild (A,B) or strong (C,D) acidification profiles. The presence of CNS isolates is displayed as relative abundance, calculated based on number of isolates (N). The bacterial species were identified as Staphylococcus xylosus (black bars), Staphylococcus saprophyticus (dark gray bars), Staphylococcus equorum (light gray bars), and Staphylococcus carnosus (white bars).

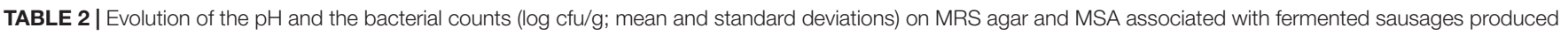
in triplicate on pilot-scale, in the presence of two different initial glucose concentrations resulting in two distinct acidification profiles.

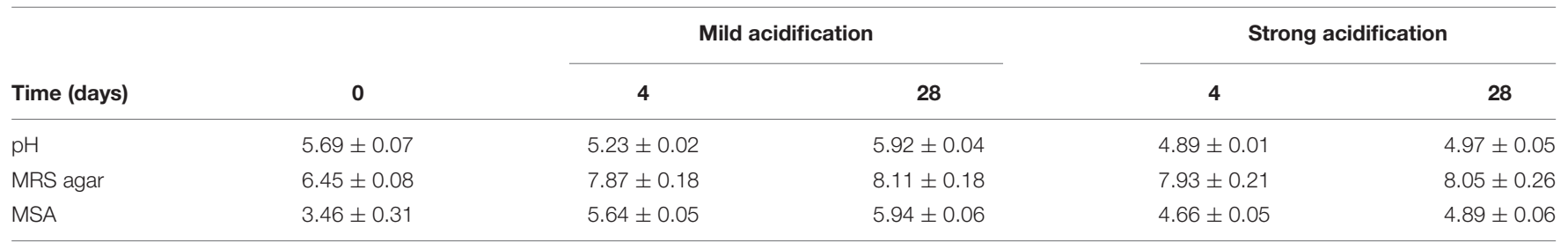

$\mathrm{pH}$ decreased from 5.69 to 4.89 after 4 days of fermentation and then slightly increased after 28 days to 4.97 . For all batches, the MRS agar counts were $6.45 \mathrm{log} \mathrm{cfu} / \mathrm{g}$ after inoculation and the ones on MSA equaled to $3.46 \mathrm{log} \mathrm{cfu} / \mathrm{g}$. The LAB population followed a similar pattern in both batches independent of the level of acidification, increasing at the end of fermentation to $7.87 \log \mathrm{cfu} / \mathrm{g}$ and further at $8.11 \mathrm{log} \mathrm{cfu} / \mathrm{g}$ by the end of the ripening stage. On the other hand, the $\mathrm{pH}$ profile had an effect on the bacterial counts enumerated on MSA. For the batches with a low glucose concentration, the MSA counts increased throughout the production process, reaching $5.64 \mathrm{log} \mathrm{cfu} / \mathrm{g}$ after 4 days of fermentation and $5.94 \mathrm{log} \mathrm{cfu} / \mathrm{g}$ after 28 days. In the more acidified variants, the bacterial counts on MSA increased up to $4.66 \mathrm{log} \mathrm{cfu} / \mathrm{g}$ at the end of the fermentation step and afterward reached their maximum value of $4.89 \mathrm{log} \mathrm{cfu} / \mathrm{g}$ by the end of the ripening stage. However, based on the bacterial isolates retrieved from MSA, the corresponding communities consisted mostly of non-further identified isolates that were not belonging to the CNS group as they yielded atypical colony morphology and could not be fingerprinted by (GTG) ${ }_{5}$-PCR. S. xylosus $(9 \%$ of the MSA isolates) and S. saprophyticus (3\%) were found in the sausages with a mild $\mathrm{pH}$ decrease; for the sausages with the $\mathrm{pH}$ values falling below 5.00 after 28 days, no staphylococcal isolates were retrieved. 


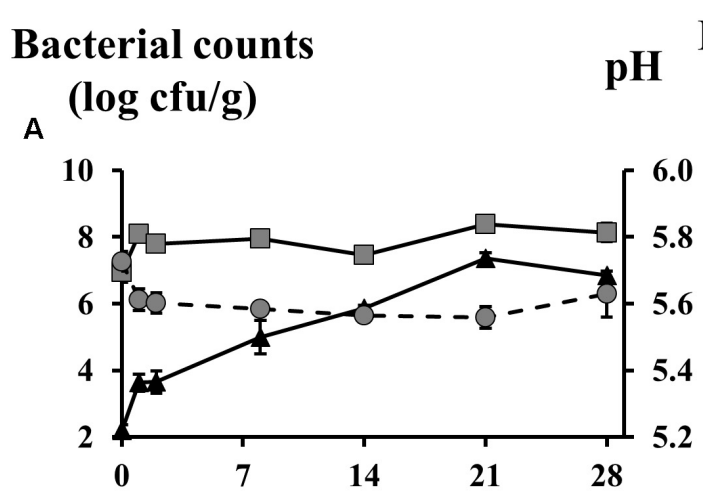

C

Presence of CNS

\section{isolates $(\%)$}

B $\quad \mathrm{N}=4 \quad \mathrm{~N}=14 \quad \mathrm{~N}=9 \quad \mathrm{~N}=19$

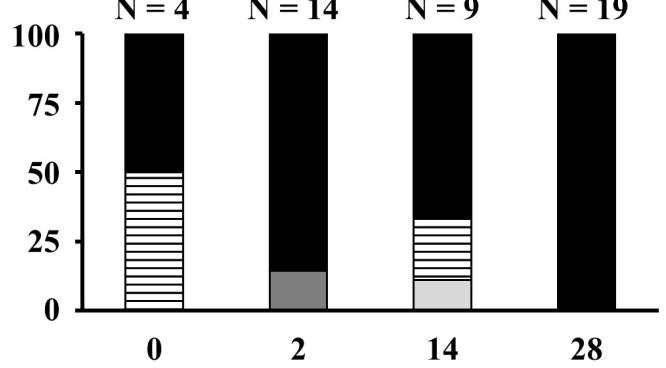

D

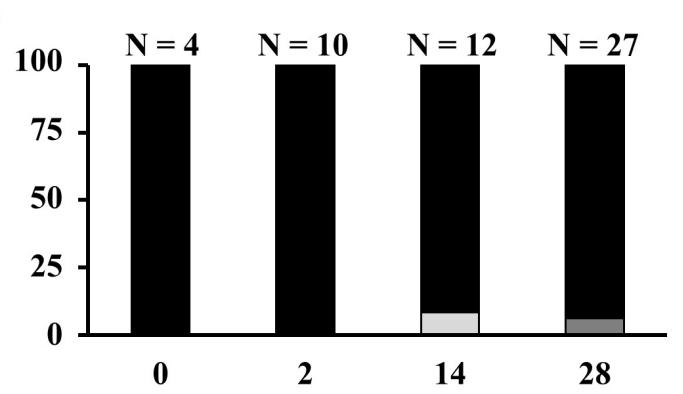

E

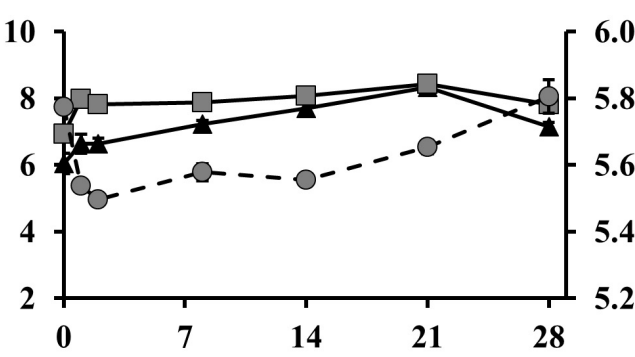

$F$

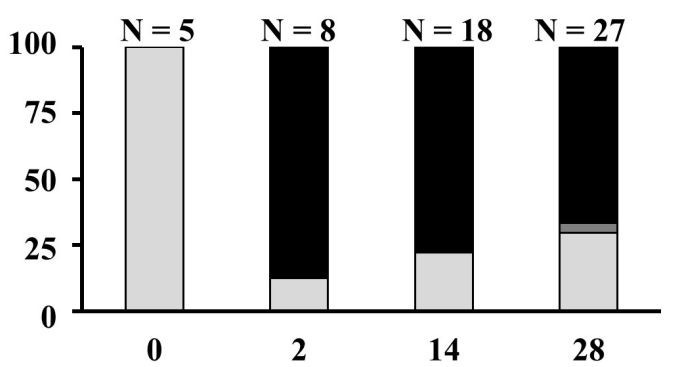

G

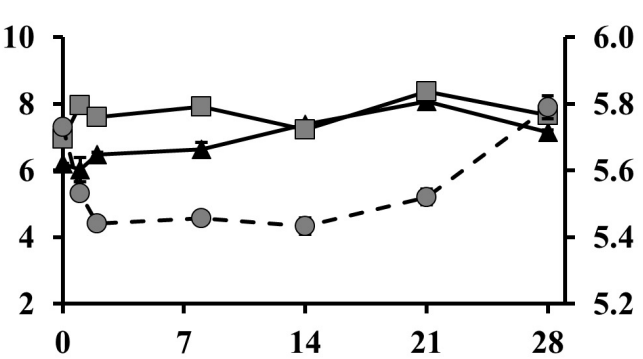

$\mathrm{H}$
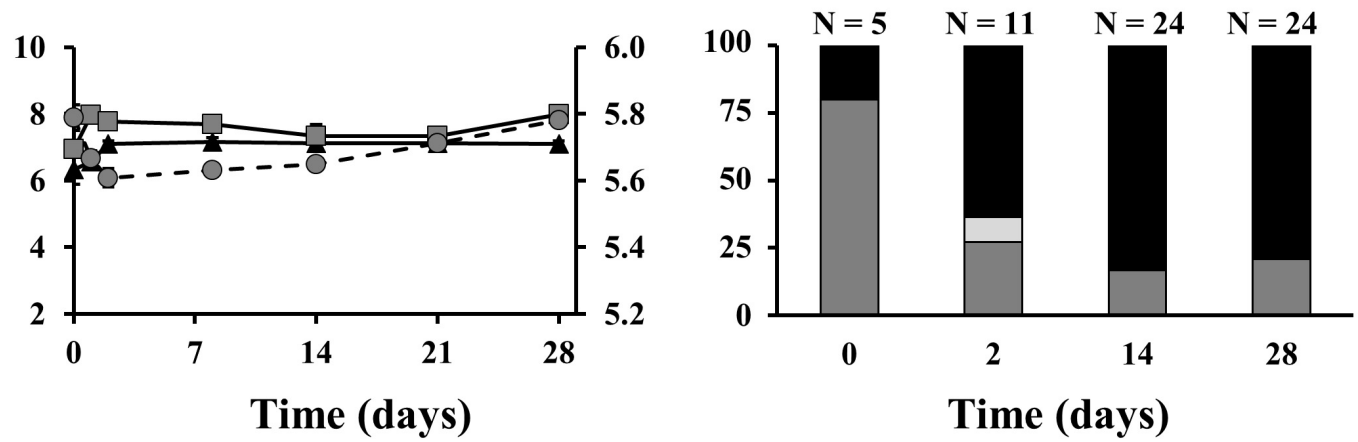

FIGURE 2 | Counts of lactic acid bacteria (gray squares) and coagulase-negative staphylococci (CNS; black triangles), as well as the pH profiles (gray circles) and the species diversity of the staphylococcal communities of fermented sausages produced on pilot-scale inoculated with different CNS strains: (A,B) Lactobacillus sakei CTC 494 without CNS strains added; (C,D) Staphylococcus xylosus 2S7-2 and L. sakei CTC 494; (E,F) Staphylococcus equorum DFL-S19 and L. sakei CTC 494; (G,H) Staphylococcus saprophyticus FPS1 and L. sakei CTC 494. The presence of CNS isolates is displayed as relative abundance, calculated based on number of isolates (N). The bacterial species were identified as Bacillus spp. (white bars with lines), S. xylosus (black bars), S. equorum (light gray bars), and S. saprophyticus (dark gray bars).

\section{Comparison of Different CNS Starter Cultures}

In the second pilot-scale sausage production experiment, no carbohydrates were added, as to meet artisan-type conditions under which CNS are normally within a comfortable $\mathrm{pH}$ range.
The initial LAB counts, as estimated on MRS agar at a level 6.80 $\log \mathrm{cfu} / \mathrm{g}$, similarly reached a ceiling level of around $8.0 \mathrm{log} \mathrm{cfu} / \mathrm{g}$ for all batches (Figure 2). As a result of this poor LAB growth, the $\mathrm{pH}$ of all batches remained above 5.40. The $\mathrm{pH}$ evolution for the 
different batches followed roughly the same pattern, decreasing during the fermentation course of 2 days and then increasing till the end of the ripening stage, especially for the batches inoculated with CNS starter cultures. The latter batches reached a final $\mathrm{pH}$ of about 5.80, whereas the batches that were not inoculated with CNS only reached 5.56. Regarding the presumable CNS counts (MSA), the control batches without added CNS had an initial population of $2.20 \log \mathrm{cfu} / \mathrm{g}$, which gradually increased to $7.36 \mathrm{log}$ $\mathrm{cfu} / \mathrm{g}$ after 21 days and subsequently decreased to $6.85 \mathrm{log} \mathrm{cfu} / \mathrm{g}$ at the end the sausage production process. The initial population of all the inoculated batches was around $6.20 \mathrm{log} \mathrm{cfu} / \mathrm{g}$. For the fermented sausages inoculated with S. equorum and S. xylosus, the MSA counts were continuously increasing till day 21 when they reached their maxima of $8.08 \mathrm{log} \mathrm{cfu} / \mathrm{g}$ and $8.33 \mathrm{log} \mathrm{cfu} / \mathrm{g}$, respectively, and then both decreased to $7.15 \mathrm{log} \mathrm{cfu} / \mathrm{g}$. The MSA counts of the batches inoculated with S. saprophyticus remained more or less stable from day 2 till the end of the ripening stage (7.10 $\log \mathrm{cfu} / \mathrm{g})$.

When exploring the CNS species diversity represented in the pool of the MSA isolates obtained, differences were seen between the four inoculation strategies (Figure 2). During the fermentations initiated with only a LAB starter culture and no added CNS (Figure 2B), S. xylosus strain(s) emerged from the background microbiota and prevailed throughout the sausage production process. The initial MSA-associated population of the meat was shared between $S$. xylosus, as the only retrieved CNS species, and Bacillus spp. (96\% sequence identity, accession number KX011931.1). The latter was also isolated after 14 days and disappeared after that. Occasional presence of S. equorum and S. saprophyticus at levels of $11 \%$ (day 14) and $14 \%$ (day 2), was also found. However, at the end of the ripening stage, S. xylosus was the only CNS species identified. Similar results were obtained from the batch inoculated with S. xylosus 2S7-2 (Figure 2D). Based on the

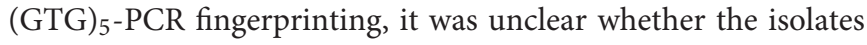
originated from the background microbiota or the starter culture added. In addition, $S$. equorum and $S$. saprophyticus were again present in minor proportions (below 8\%) at days 14 and 28, respectively. When S. saprophyticus FPS1 (Figure 2F) or S. equorum DFL-S19 (Figure 2H) were added as starter culture strains, both species managed to survive during the fermentation until day 28 but were not very competitive, since $S$. xylosus was once more the prevailing species in both cases.

\section{Volatile Compounds}

The main volatiles produced during the second pilot-scale experiment originated from physicochemical reactions, relating mostly to lipid autoxidation, as well as from the bacterial conversion of carbohydrates, amino acids, and fatty acids (Supplementary Table S1). The evolution of the volatile compounds arising from branched-chain amino acid metabolism, namely 3-methyl-butanoic acid, 2-methyl-butanoic acid, 2-methyl propanoic acid, 2-methyl-propanol, and 3methyl-butanol, is depicted in Figure 3. Differences were found between the batches after 14 days for 3-methyl-butanol ( $p=0.04), 3$-methyl-butanoic-acid $(p=0.04), 2$-methyl-butanoic acid $(p=0.04)$, and 2-methyl-propanoic acid $(p=0.02)$. At the end of the ripening (28 days), inter-batch differences were limited to 2-methyl-butanoic acid $(p=0.02)$ and 2-methyl-propanoic acid $(p=0.04)$.

After 14 days, the level of 3-methyl-butanol in the batch inoculated with S. xylosus 2S7-2 did not differ significantly from the one with $S$. equorum DFL-S19 but was higher than in the control $(p=0.05)$ and the batch inoculated with $S$. saprophyticus FPS1 $(p=0.05)$. The level of its corresponding carboxylic acid, 3-methyl-butanoic acid, did not differ between the various inoculated batches but was always higher than in the control after 14 days $(p=0.05)$. Isoleucine-derived 2-methyl-butanoic acid was also higher in all inoculated batches than in the control after both 14 days $(p=0.05)$ and 28 days $(p=0.05)$. Finally, valine-derived 2methyl-propanoic acid was higher in all inoculated batches than in the control after 14 days $(p=0.05)$, but not after 28 days. At this stage, only $S$. equorum DFL-S19 displayed still higher levels, not only with respect to the control $(p=0.05)$ but also compared to the other inoculated batches $(p=0.05)$.

\section{DISCUSSION}

Staphylococcus equorum, S. saprophyticus, and S. xylosus are usually the most prevalent CNS species in spontaneously fermented sausages of the Mediterranean type (García-Varona et al., 2000; Papamanoli et al., 2002; Drosinos et al., 2005; Fonseca et al., 2013b; Greppi et al., 2015; Pisacane et al., 2015). The present study contributes to a further validation of this typical association, related to fermented sausages that have low to mild acidification profiles. The experiment using fermented mince-based meat models without added CNS indicated that S. xylosus became the leading CNS species during the first days of fermentation and was then accompanied by either S. equorum in the mildly acidified batches and by $S$. saprophyticus in the most acid variants. It has indeed been suggested previously that the latter CNS species is somewhat more fit at low $\mathrm{pH}$ values than S. equorum (Janssens et al., 2013). Note also that a minor fraction of $S$. carnosus emerged in the batches with the lowest $\mathrm{pH}$, as this CNS species is known for its robustness toward acidic conditions but poor adaptation to higher $\mathrm{pH}$ values (Stavropoulou et al., 2018a). Comparison of the evolution of the bacterial species diversity with the $\mathrm{pH}$ dynamics further suggested that $S$. xylosus was the most competitive CNS species within the initial $\mathrm{pH}$ window of fermentation ( $\mathrm{pH} 5.3-5.8$ ), but that a $\mathrm{pH}$ of 5.3 served as a breakpoint after which either S. equorum or S. saprophyticus took over, depending on the extent of the further $\mathrm{pH}$ drop. Of course, it needs to be taken into account that the decrease of temperature from 20 to $18^{\circ} \mathrm{C}$ also may have had a modulating effect, taking into account that $S$. equorum is rather well adapted to low temperatures, provided that the $\mathrm{pH}$ is not too low (Mauriello et al., 2004; Leroy et al., 2009).

When investigating the effect of $\mathrm{pH}$ in fermented sausages on pilot-scale production level, a $\mathrm{pH}$ drop below 5.3 resulted overall in a poor growth of the CNS communities. At the end of the ripening stage, the duo of S. xylosus and S. saprophyticus was still found in the moderately acidified batches, albeit in minor 


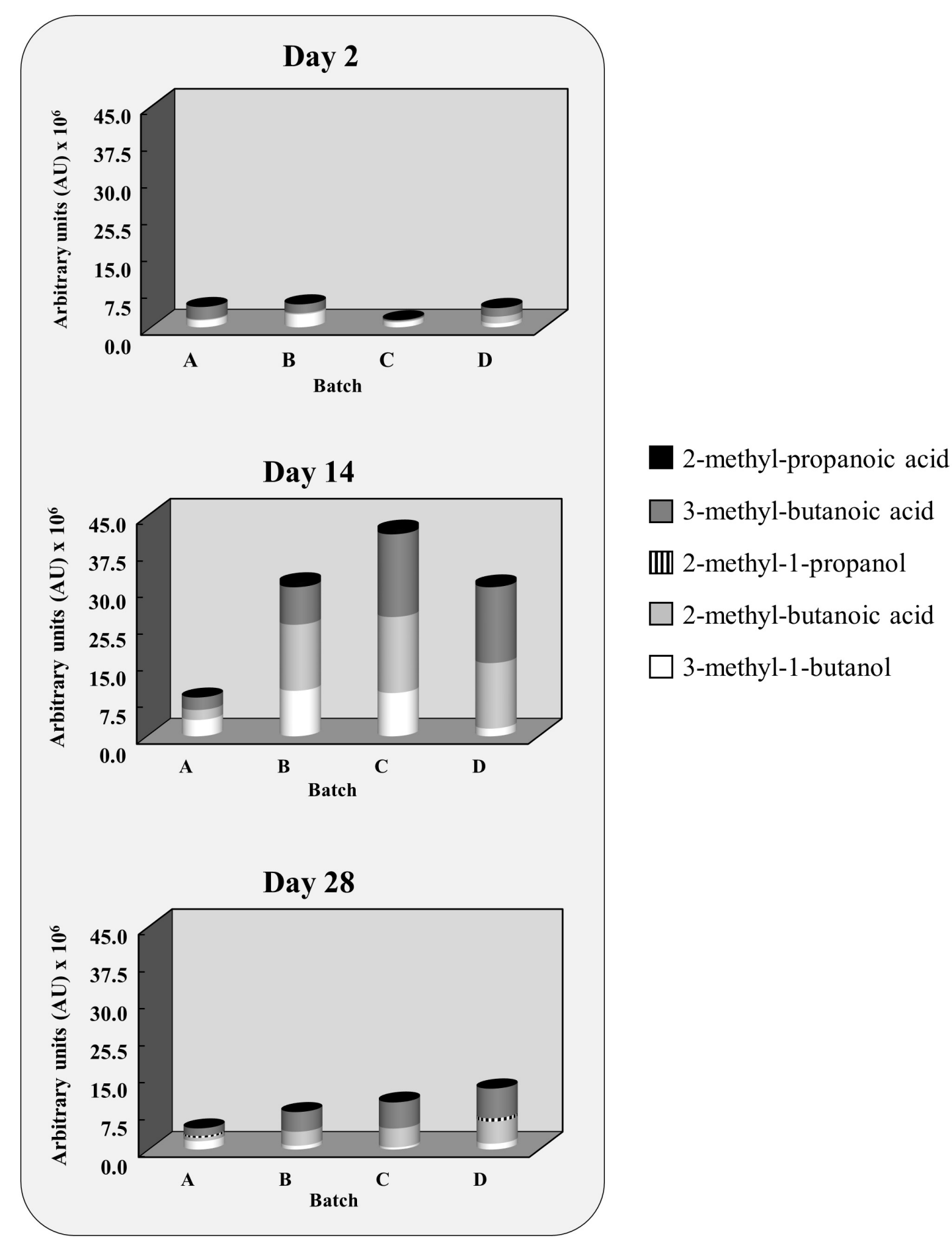

FIGURE 3 | Evolution of the area of the volatile compounds resulting from branched-chain amino acid conversion after 2, 14, and 28 days. Batches with (A) no CNS added or inoculated with (B) Staphylococcus xylosus 2S7-2, (C) Staphylococcus equorum DFL-S19, or (D) Staphylococcus saprophyticus FPS1.

proportions, but no CNS were retrieved from the batches in which the $\mathrm{pH}$ dropped below 5.0 during fermentation. The degree of acidification does indeed not only shape the composition of the staphylococcal communities during meat fermentations but also their levels (Janssens et al., 2013; Stavropoulou et al., 2018a,b). As a result, the CNS communities in Southern-European fermented meat products (Iacumin et al., 2012; Fonseca et al., 2013b; Aquilanti et al., 2016) provide a potentially important contrast to the ones in highly acidified Northern-European variants in which CNS are limited in terms of both numbers and diversity and thus 
potentially also with respect to quality-yielding functionalities (Ravyts et al., 2010).

When the acidity stress on the CNS communities was minimized by preparing fermented sausages without added carbohydrates, to limit the $\mathrm{pH}$ drop by the LAB, the fate of the three CNS species upon addition as starter culture strains revealed two clear patterns. First, superiority of $S$. xylosus within this very mild $\mathrm{pH}$ context $(\mathrm{pH}>5.4$ at all times) was seen in all batches, either due to the background microbiota (in the absence of the starter culture strain S. xylosus 2S7-2) or to the added starter culture strain S. xylosus 2S7-2. In the latter case, the applied methodology did not allow to differentiate the added strain of S. xylosus from S. xylosus strains within the background microbiota. A limitation of the (GTG) $)_{5}-\mathrm{PCR}$ classification and identification technique consists of its suboptimal resolution to differentiate on intraspecies level within the CNS group (Braem et al., 2011). The results obtained thus indicated that S. xylosus was well-adapted to the specificities of the recipe and technology applied in the experiment. This may partially be ascribed to the very moderate $\mathrm{pH}$ levels, taking into consideration that $S$. xylosus habitually prevails at such conditions (Cocolin et al., 2001a,b; Blaiotta et al., 2004; Iacumin et al., 2006) and possesses great ability in adapting to the meat environment (Mauriello et al., 2004; Drosinos et al., 2005; Planchon et al., 2006; Vermassen et al., 2014, 2016a,b; Leroy et al., 2017). This staphylococcal species is commonly isolated from different ecosystems and is known to adapt to various substrates (Nagase et al., 2002; Shale et al., 2005; Dordet-Frisoni et al., 2007).

As a second pattern, it became clear that added cultures of S. saprophyticus FPS1 and S. equorum DFL-S19 were only present in high proportions at the day of inoculation and were subsequently outcompeted by naturally occurring S. xylosus strain(s), once more suggesting their reduced fitness above the transition point of $\mathrm{pH}$ 5.3. The ability of the starter cultures to compete and overrule the background microbiota is a key criterion for starter culture selection and is not always guaranteed (Fonseca et al., 2013c; Stavropoulou et al., 2018a). For several CNS strains that are selected as starter cultures based on desirable metabolic traits, failure to survive and prevail in real food matrices has been reported (Villani et al., 2007; Sánchez Mainar and Leroy, 2015). Even the highly adapted and recurrent species of $S$. equorum and S. saprophyticus can thus become disadvantaged under certain production scenarios.

Coagulase-negative staphylococci are a metabolically heterogeneous group and can thus affect the quality of the endproducts (Sánchez Mainar et al., 2017). During the present study, the volatile analysis indicated differences between the control batch and the inoculated ones as well as between the batches that were inoculated with different CNS strains, especially for the metabolites arising from amino acid conversion. Branched-chain amino acid-derived metabolites produced by CNS, such as 3-methyl butanol and 3-methyl butanoic acid, are commonly found in dry fermented sausages and play an important role in the typical aroma of those products (Beck et al., 2004; Ravyts et al., 2010). However, their production in vitro or/and in situ differs among species and even strains (Ravyts et al., 2010; Stavropoulou et al., 2015). The addition of the starter culture strains modified the volatile profiles, even when the inoculated strains were not the prevailing ones at the end of the ripening process. In previous studies, it has been demonstrated that non-dominant CNS species can sometimes be more metabolically active than the dominant ones, thus contributing to the quality traits of the end-product (Greppi et al., 2015).

In conclusion, the species diversity of CNS in fermented meats is variable and depends on the processing conditions applied. Among the different influencing factors, the raw materials harboring the background microbiota and the degree of acidification are of particularly relevance. The present study demonstrated through a combination of experimental set-ups that the $\mathrm{pH}$ could finetune the relative occurrence of the three main CNS species spontaneously associated with sausage fermentation, making abstraction of S. carnosus that mostly seems relevant as a starter culture in highly acidified fermented meats. Of course, the findings related to the effect of $\mathrm{pH}$ could not be completely untangled from the other conditions that prevail in the meat matrix, with a particular need to further explore the effects of curing salt, temperature, oxygen gradients, spices, and water activity. In addition, and despite the fact that the findings seemed rather robust on species level, intraspecies variability merits further investigation.

\section{AUTHOR CONTRIBUTIONS}

DAS contributed to the experimental work, the acquisition, processing, and interpretation of the data, and the drafting of the manuscript. HDM, $\mathrm{AB}, \mathrm{BJ}$, and $\mathrm{PF}$ contributed to the experimental work and the acquisition, processing, and interpretation of the data. LDV and SDS contributed to interpretation of the data and the drafting of the manuscript. FL contributed to the design of the work plan, the interpretation of the data, and the drafting of the manuscript.

\section{FUNDING}

The authors acknowledge the financial support of the Research Council of the Vrije Universiteit Brussel (SRP7, IRP2, HOA, and IOF342 projects), the Hercules Foundation (projects UABR 09/004 and UAB 13/002), and the Research Foundation Flanders (project FWOAL632).

\section{ACKNOWLEDGMENTS}

This work is dedicated to the memory of Ph.D. student Maarten Janssens, who also participated in this study.

\section{SUPPLEMENTARY MATERIAL}

The Supplementary Material for this article can be found online at: https://www.frontiersin.org/articles/10.3389/fmicb.2018. 02232/full\#supplementary-material 


\section{REFERENCES}

Aguinaga, N., Campillo, N., Vinas, P., and Hernandez-Cordoba, M. (2008). A headspace solid phase microextraction procedure coupled with gas chromatography - mass spectrometry for the analysis of volatile polycyclic aromatic hydrocarbons in milk samples. Anal. Bioanal. Chem. 391, 753-758. doi: 10.1007/s00216-008-1841-2

Aquilanti, L., Garofalo, C., Osimani, A., and Clementi, F. (2016). Ecology of lactic acid bacteria and coagulase-negative cocci in fermented dry sausages manufactured in Italy and other Mediterranean countries: an overview. Int. Food Res. J. 23, 429-445.

Beck, H. C., Hansen, A. M., and Lauritsen, F. R. (2002). Metabolite production and kinetics of branched-chain aldehyde oxidation in Staphylococcus xylosus. Enzyme Microb. Tech. 31, 94-101. doi: 10.1016/S0141-0229(02)00067-4

Beck, H. C., Hansen, A. M., and Lauritsen, F. R. (2004). Catabolism of leucine to branched-chain fatty acids in Staphylococcus xylosus. J. Appl. Microbiol. 96, 1185-1193. doi: 10.1111/j.1365-2672.2004.02253.x

Blaiotta, G., Pennacchia, C., Villani, F., Ricciardi, A., Tofalo, R., and Parente, E. (2004). Diversity and dynamics of communities of coagulase-negative staphylococci in traditional fermented sausages. J. Appl. Microbiol. 97, 271-284. doi: 10.1111/j.1365-2672.2004.02298.x

Bonomo, M. G., Ricciardi, A., and Salzano, G. (2011). Influence of autochthonous starter cultures on microbial dynamics and chemical-physical features of traditional fermented sausages of Basilicata region. World J. Microbiol. Biotech. 27, 137-146. doi: 10.1007/s11274-010-0439-y

Braem, G., De Vliegher, S., Supré, K., Haesebrouck, F., Leroy, F., and De Vuyst, L. (2011). (GTG)5-PCR fingerprinting for the classification and identification of coagulase-negative Staphylococcus species from bovine milk and teat apices: a comparison of type strains and field isolates. Vet. Microbiol. 147, 67-74. doi: 10.1016/j.vetmic.2010.05.044

Casaburi, A., Blaiotta, G., Mauriello, G., Pepe, O., and Villani, F. (2005). Technological activities of Staphylococcus carnosus and Staphylococcus simulans strains isolated from fermented sausages. Meat Sci. 71, 643-650. doi: 10.1016/j. meatsci.2005.05.008

Casquete, R., Benito, M. J., Martín, A., Ruiz-Moyano, S., Córdoba, J. J., and Córdoba, M. G. (2011). Role of an autochthonous starter culture and the protease EPg222 on the sensory and safety properties of a traditional Iberian dry-fermented sausage "salchichón". Food Microbiol. 28, 1432-1440. doi: 10. 1016/j.fm.2011.07.004

Cocolin, L., Manzano, M., Aggio, D., Cantoni, C., and Comi, G. (2001a). A novel polymerase chain reaction (PCR)-denaturing gradient gel electrophoresis (DGGE) for the identification of Micrococcaceae strains involved in meat fermentations. Its application to naturally fermented Italian sausages. Meat Sci. 58, 59-64.

Cocolin, L., Manzano, M., Cantoni, C., and Comi, G. (2001b). Denaturing gradient gel electrophoresis analysis of the $16 \mathrm{~S}$ rRNA gene $\mathrm{V} 1$ region to monitor dynamic changes in the bacterial population during fermentation of Italian sausages. Appl. Environ. Microbiol. 67, 5113-5121.

Corbière Morot-Bizot, S., Leroy, S., and Talon, R. (2006). Staphylococcal community of a small unit manufacturing traditional dry fermented sausages. Int. J. Food Microbiol. 108, 210-217. doi: 10.1016/j.ijfoodmicro.2005. 12.006

Corbière Morot-Bizot, S., Leroy, S., and Talon, R. (2007). Monitoring of staphylococcal starters in two French processing plants manufacturing dry fermented sausages. J. Appl. Microbiol. 102, 238-244. doi: 10.1111/j.1365-2672. 2006.03041.x

Coton, E., Desmonts, M. H., Leroy, S., Coton, M., Jamet, E., Christieans, S., et al. (2010). Biodiversity of coagulase-negative staphylococci in French cheeses, dry fermented sausages, processing environments and clinical samples. Int. J. Food Microbiol. 137, 221-229. doi: 10.1016/j.ijfoodmicro.2009.11.023

Di Cagno, R., Chaves Lopez, C., Tofalo, R., Gallo, G., De Angelis, M., Paparella, A., et al. (2008). Comparison of the compositional, microbiological, biochemical and volatile profile characteristics of three Italian PDO fermented sausages. Meat Sci. 79, 224-235. doi: 10.1016/j.meatsci.2007.09.006

Di Maria, S., Basso, A. L., Santoro, E., Grazia, L., and Coppola, R. (2002). Monitoring of Staphylococcus xylosus DSM 20266 added as starter culture during fermentation and ripening of soppressata molisana, a typical Italian sausage. J. Appl. Microbiol. 92, 158-164. doi: 10.1046/j.1365-2672.2002.01512.x
Dordet-Frisoni, E., Dorchies, G., De Araujo, C., Talon, R., and Leroy, S. (2007). Genomic diversity in Staphylococcus xylosus. Appl. Environ. Microb. 73, 7199-7209. doi: 10.1128/AEM.01629-07

Drosinos, E. H., Mataragas, M., Xiraphi, N., Moschonas, G., Gaitis, F., and Metaxopoulos, J. (2005). Characterization of the microbial flora from a traditional Greek fermented sausage. Meat Sci. 69, 307-317. doi: 10.1016/j. meatsci.2004.07.012

Drosinos, E. H., Paramithiotis, S., Kolovos, G., Tsikouras, I., and Metaxopoulos, I. (2007). Phenotypic and technological diversity of lactic acid bacteria and staphylococci isolated from traditionally fermented sausages in southern Greece. Food Microbiol. 24, 260-270. doi: 10.1016/j.fm.2006.05.001

Fonseca, S., Cachaldora, A., Gómez, M., Franco, I., and Carballo, J. (2013a). Effect of different autochthonous starter cultures on the volatile compounds profile and sensory properties of Galician chorizo, a traditional Spanish dry fermented sausage. Food Control 33, 6-14. doi: 10.1016/j.foodcont.2013.01.040

Fonseca, S., Cachaldora, A., Gómez, M., Franco, I., and Carballo, J. (2013b). Monitoring the bacterial population dynamics during the ripening of Galician chorizo, a traditional dry fermented Spanish sausage. Food Microbiol. 33, 77-84. doi: 10.1016/j.fm.2012.08.015

Fonseca, S., Ivette Ouoba, L. I., Franco, I., and Carballo, J. (2013c). Use of molecular methods to characterize the bacterial community and to monitor different native starter cultures throughout the ripening of Galician chorizo. Food Microbiol. 34, 215-226. doi: 10.1016/j.fm.2012.12.006

García-Varona, M., Santos, M. E., Jaime, I., and Rovira, J. (2000). Characterisation of Micrococcaceae isolated from different varieties of chorizo. Int. J. Food Microbiol. 54, 189-195. doi: 10.1016/S0168-1605(99)00192-0

Greppi, A., Ferrocino, I., La Storia, A., Rantsiou, K., Ercolini, D., and Cocolin, L. (2015). Monitoring of the microbiota of fermented sausages by culture independent rRNA-based approaches. Int. J. Food Microbiol. 212, 67-75. doi: 10.1016/j.ijfoodmicro.2015.01.016

Iacumin, L., Comi, G., Cantoni, C., and Cocolin, L. (2006). Ecology and dynamics of coagulase-negative cocci isolated from naturally fermented Italian sausages. Syst. Appl. Microbiol. 29, 480-486. doi: 10.1016/j.syapm.2005.11.006

Iacumin, L., Manzano, M., and Comi, G. (2012). Catalase-positive cocci in fermented sausage: variability due to different pork breeds, breeding systems and sausage production technology. Food Microbiol. 29, 178-186. doi: 10.1016/ j.fm.2011.09.005

Janssens, M., Myter, N., De Vuyst, L., and Leroy, F. (2013). Community dynamics of coagulase-negative staphylococci during spontaneous artisan-type meat fermentations differ between smoking and moulding treatments. Int. J. Food Microbiol. 166, 168-175. doi: 10.1016/j.ijfoodmicro.2013.06.034

Kolb, B., and Ettre, L. S. (2006). Static Headspace - Gas Chromatography: Theory and Practice. Hoboken, NJ: John Wiley \& Sons. doi: 10.1002/0471914584

Leroy, F., Goudman, T., and De Vuyst, L. (2014). "The influence of processing parameters on starter culture performance," in Handbook of Fermented Meat and Poultry, 2nd Edn, ed. F. Toldrá (Oxford: Blackwell), 169-175.

Leroy, F., Scholliers, P., and Amilien, V. (2015). Elements of innovation and tradition in meat fermentation: conflicts and synergies. Int. J. Food Microbiol. 212, 2-8. doi: 10.1016/j.ijfoodmicro.2014.11.016

Leroy, F., Verluyten, J., and De Vuyst, L. (2006). Functional meat starter cultures for improved sausage fermentation. Int. J. Food Microbiol. 106, 270-285. doi: 10.1016/j.ijfoodmicro.2005.06.027

Leroy, S., Lebert, I., Chacornac, J. P., Chavant, P., Bernardi, T., and Talon, R. (2009). Genetic diversity and biofilm formation of Staphylococcus equorum isolated from naturally fermented sausages and their manufacturing environment. Int. J. Food Microbiol. 134, 46-51. doi: 10.1016/j.ijfoodmicro.2008.12.012

Leroy, S., Vermassen, A., Ras, G., and Talon, R. (2017). Insight into the genome of Staphylococcus xylosus, a ubiquitous species well adapted to meat products. Microorganisms 5:52. doi: 10.3390/microorganisms5030052

Marty, E., Bodenmann, C., Buchs, J., Hadorn, R., Eugster-Meier, E., Lacroix, C., et al. (2012). Prevalence of antibiotic resistance in coagulase-negative staphylococci from spontaneously fermented meat products and safety assessment for new starters. Int. J. Food Microbiol. 159, 74-83. doi: 10.1016/j. ijfoodmicro.2012.07.025

Mauriello, G., Casaburi, A., Blaiotta, G., and Villani, F. (2004). Isolation and technological properties of coagulase negative staphylococci from fermented sausages of Southern Italy. Meat Sci. 67, 149-158. doi: 10.1016/j.meatsci.2003. 10.003 
Nagase, N., Sasaki, A., Yamashita, K., Shimizu, A., Wakita, Y., Kitai, S., et al. (2002). Isolation and species distribution of staphylococci from animal and human skin. J. Vet. Med. Sci. 64, 245-250. doi: 10.1292/jvms.64.245

Olesen, P. T., Stahnke, L. H., and Talon, R. (2004). Effect of ascorbate, nitrate and nitrite on the amount of flavour compounds produced from leucine by Staphylococcus xylosus and Staphylococcus carnosus. Meat Sci. 68, 193-200. doi: 10.1016/j.meatsci.2004.02.017

Papamanoli, E., Kotzekidou, P., Tzanetakis, N., and Litopoulou-Tzanetaki, E. (2002). Characterization of Micrococcaceae isolated from dry fermented sausage. Food Microbiol. 19, 441-449. doi: 10.1006/fmic.2002.0503

Pisacane, V., Callegari, M. L., Puglisi, E., Dallolio, G., and Rebecchi, A. (2015). Microbial analyses of traditional Italian salami reveal microorganisms transfer from the natural casing to the meat matrix. Int. J. Food Microbiol. 207, 57-65. doi: 10.1016/j.ijfoodmicro.2015.04.029

Planchon, S., Gaillard-Martinie, B., Dordet-Frisoni, E., Bellon-Fontaine, M. N., Leroy, S., Labadie, J., et al. (2006). Formation of biofilm by Staphylococcus xylosus. Int. J. Food Microbiol. 109, 88-96. doi: 10.1016/j.ijfoodmicro.2006. 01.016

Prpich, N. Z. P., Garro, O. A., Romero, M., Judis, M. A., Cayré, M. E., and Castro, M. P. (2016). Evaluation of an autochthonous starter culture on the production of a traditional dry fermented sausage from Chaco (Argentina) at a small-scale facility. Meat Sci. 115, 41-44. doi: 10.1016/j.meatsci.2016.01.005

Ratsimba, A., Leroy, S., Chacornac, J. P., Rakoto, D., Arnaud, E., Jeannoda, V., et al. (2017). Staphylococcal ecosystem of kitoza, a traditional malagasy meat product. Int. J. Food Microbiol. 246, 20-24. doi: 10.1016/j.ijfoodmicro.2017. 02.001

Ravyts, F., Steen, L., Goemaere, O., Paelinck, H., De Vuyst, L., and Leroy, F. (2010). The application of staphylococci with flavour-generating potential is affected by acidification in fermented dry sausages. Food Microbiol. 27, 945-954. doi: 10.1016/j.fm.2010.05.030

Rosenstein, R., Nerz, C., Biswas, L., Resch, A., Raddatz, G., Schuster, S. C., et al. (2009). Genome analysis of the meat starter culture bacterium Staphylococcus carnosus TM300. Appl. Environ. Microbiol. 75, 811-822. doi: 10.1128/AEM. 01982-08

Rossi, F., Tofalo, R., Torriani, S., and Suzzi, G. (2001). Identification by 16S-23S rDNA intergenic region amplification, genotypic and phenotypic clustering of Staphylococcus xylosus strains from dry sausages. J. Appl. Microbiol. 90, 365-371. doi: 10.1046/j.1365-2672.2001.01254.x

Sánchez Mainar, M., and Leroy, F. (2015). Process-driven bacterial community dynamics are key to cured meat colour formation by coagulase-negative staphylococci via nitrate reductase or nitric oxide synthase activities. Int. J. Food Microbiol. 212, 60-66. doi: 10.1016/j.ijfoodmicro.2015.03.009

Sánchez Mainar, M., Stavropoulou, D. A., and Leroy, F. (2017). Exploring the metabolic potential of coagulase-negative staphylococci to improve the quality and safety of fermented meats: a review. Int. J. Food Microbiol. 247, 24-37. doi: 10.1016/j.ijfoodmicro.2016.05.021

Shale, K., Lues, J. F. R., Venter, P., and Buys, E. M. (2005). The distribution of Staphylococcus sp. on bovine meat from abattoir deboning rooms. Food Microbiol. 22, 433-438. doi: 10.1016/j.fm.2004.09.007

Stahnke, L. H., Holck, A., Jensen, A., Nilsen, A., and Zanardi, E. (2002). Maturity acceleration of Italian dried sausage by Staphylococcus carnosus - relationship between maturity and flavor compounds. J. Food Sci. 67, 1914-1921. doi: 10. 1111/j.1365-2621.2002.tb08746.x
Stavropoulou, D. A., Borremans, W., De Vuyst, L., De Smet, S. and Leroy, F. (2015). Amino acid conversions by coagulase-negative staphylococci in a rich medium: assessment of inter- and intraspecies heterogeneity. Int. J. Food Microbiol. 212, 34-40. doi: 10.1016/j.ijfoodmicro.2015.04.048

Stavropoulou, D. A., De Maere, H., Berardo, A., Janssens, B., Fillipou, P., De Vuyst, L., et al. (2018a). Pervasiveness of Staphylococcus carnosus over Staphylococcus xylosus is affected by the level of acidification within a conventional meat starter culture set-up. Int. J. Food Microbiol. 274, 60-66. doi: 10.1016/j.ijfoodmicro.2018.03.006

Stavropoulou, D. A., Van Reckem, E., De Vuyst, L., De Smet, S., and Leroy, F. (2018b). The narrowing down of inoculated communities of coagulase-negative staphylococci in fermented meat models is modulated by temperature and $\mathrm{pH}$. Int. J. Food Microbiol. 274, 52-59. doi: 10.1016/j.ijfoodmicro.2018.03.008

Talon, R., Leroy, S., and Lebert, I. (2007). Microbial ecosystems of traditional fermented meat products: the importance of indigenous starters. Meat Sci. 77, 55-62. doi: 10.1016/j.meatsci.2007.04.023

Talon, R., Leroy, S., Lebert, I., Giammarinaro, P., Chacornac, J. P., LatorreMoratalla, M., et al. (2008). Safety improvement and preservation of typical sensory qualities of traditional dry fermented sausages using autochthonous starter cultures. Int. J. Food Microbiol. 126, 227-234. doi: 10.1016/j.ijfoodmicro. 2008.05.031

Tjener, K., Stahnke, L. H., Andersen, L., and Martinussen, J. (2004). The pHunrelated influence of salt, temperature and manganese on aroma formation by Staphylococcus xylosus and Staphylococcus carnosus in a fermented meat model system. Int. J. Food Microbiol. 97, 31-42. doi: 10.1016/j.ijfoodmicro.2004.04.007

Vermassen, A., de La Foye, A., Loux, V., Talon, R., and Leroy, S. (2014). Transcriptomic analysis of Staphylococcus xylosus in the presence of nitrate and nitrite in meat reveals its response to nitrosative stress. Front. Microbiol. 5:691. doi: $10.3389 /$ fmicb.2014.00691

Vermassen, A., Dordet-Frisoni, E., de La Foye, A., Micheau, P., Laroute, V., Leroy, S., et al. (2016a). Adaptation of Staphylococcus xylosus to nutrients and osmotic stress in a salted meat model. Front. Microbiol. 7:87. doi: 10.3389/fmicb. 2016.00087

Vermassen, A., Talon, R., and Leroy, S. (2016b). Ferritin, an iron source in meat for Staphylococcus xylosus? Int. J. Food Microbiol. 225, 20-26. doi: 10.1016/j. ijfoodmicro.2016.03.005

Villani, F., Casaburi, A., Pennacchia, C., Filosa, L., Russo, F., and Ercolini, D. (2007). Microbial ecology of the soppressata of Vallo di Diano, a traditional dry fermented sausage from Southern Italy, and in vitro and in situ selection of autochthonous starter cultures. Appl. Environ. Microbiol. 73, 5453-5463. doi: 10.1128/AEM.01072-07

Conflict of Interest Statement: The authors declare that the research was conducted in the absence of any commercial or financial relationships that could be construed as a potential conflict of interest.

Copyright (c) 2018 Stavropoulou, De Maere, Berardo, Janssens, Filippou, De Vuyst, De Smet and Leroy. This is an open-access article distributed under the terms of the Creative Commons Attribution License (CC BY). The use, distribution or reproduction in other forums is permitted, provided the original author(s) and the copyright owner(s) are credited and that the original publication in this journal is cited, in accordance with accepted academic practice. No use, distribution or reproduction is permitted which does not comply with these terms. 